\title{
The association of priori and posteriori dietary patterns with the risk of incident hypertension: Tehran Lipid and Glucose Study
}

\author{
Azra Ramezankhani ${ }^{1}$, Firoozeh Hosseini-Esfahani ${ }^{*}{ }^{*}$, Parvin Mirmiran ${ }^{2 *}$, Fereidoun Azizi ${ }^{3}$ and Farzad Hadaegh ${ }^{1}$
}

\begin{abstract}
Background: The aim of this study was to investigate the association of dietary patterns with incident hypertension.

Materials/methods: This prospective study was conducted on 4793 individuals of Tehran lipid and glucose study participants, aged $\geq 18$ years who were followed for a median of 6.3 years from 2008-2011 to 2016-2018. A valid and reliable semi-quantitative food frequency questionnaire was used to assess usual dietary intakes. Anthropometrics and blood pressure were assessed at baseline and during follow up examinations. Dietary patterns were derived using principal component analysis (PCA). Healthy eating index (HEI) and dietary approach to stop hypertension (DASH) score were measured based on dietary recommendations. Time-dependent Cox models adjusting for confounders were used to examine the association between dietary patterns and the risk of hypertension.

Results: During follow-up, a total of 727 incident cases of hypertension were identified. The mean \pm SD age at baseline was $40.3 \pm 13.5$ and $37.9 \pm 12.1$ years in men and women, respectively. Two dietary patterns (the healthy and unhealthy) were extracted by PCA. Compared with participants in the first quartile, a 23\% (HR: 1.23; 95\%Cl 1.00-1.53; P trend: 0.056 ) increased risk of hypertension was found in the fourth quartile of HEl score. This association was disappeared after further adjustment for confounders. Increasing DASH score, the healthy and unhealthy dietary pattern were not associated with risk of hypertension.
\end{abstract}

Conclusion: Our findings showed that higher adherences to the posteriori- and priori-dietary patterns were not associated with risk of hypertension in this population.

Keywords: Blood pressure, Hypertension, Dietary pattern, Healthy eating index, Factor analysis, Diet

\section{Background}

Hypertension is an important public health concern affecting more than $40 \%$ of people aged $>25$ years worldwide [1]. It has long been recognized that hypertension is an important risk factor for cardiovascular disease (CVD) and accounts for $50 \%$ of all ischemic heart diseases and stroke events (2). Hypertension is a multi-factorial

\footnotetext{
${ }^{*}$ Correspondence: f.hosseini@sbmu.ac.ir; mirmiran@endocrine.ac.ir

${ }^{2}$ Nutrition and Endocrine Research Center, Research Institute

for Endocrine Sciences, Shahid Beheshti University of Medical Sciences, Tehran, Iran

Full list of author information is available at the end of the article
}

disease resulting from complex interactions between diet, lifestyle and genetic risk factors [2-4]. Most epidemiological studies on the relationships between nutrition and hypertension have focused on a single food/nutrient (e.g. coffee and caffeine, dairy, cruciferous vegetables, etc.) [5, 6]. However, it is often difficult to separate out the specific effects of a single nutrient or food [6,7]; because, people naturally eat a combination of many different foods that may exhibit complicated interactions or synergistic effects. Therefore, dietary pattern analysis has been suggested as an alternative approach to study the relation between disease and dietary intake [7]. Two methodologies have been suggested: the priori approach

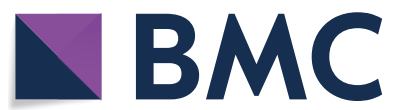

(c) The Author(s) 2021. This article is licensed under a Creative Commons Attribution 4.0 International License, which permits use, sharing, adaptation, distribution and reproduction in any medium or format, as long as you give appropriate credit to the original author(s) and the source, provide a link to the Creative Commons licence, and indicate if changes were made. The images or other third party material in this article are included in the article's Creative Commons licence, unless indicated otherwise in a credit line to the material. If material is not included in the article's Creative Commons licence and your intended use is not permitted by statutory regulation or exceeds the permitted use, you will need to obtain permission directly from the copyright holder. To view a copy of this licence, visit http://creativeco mmons.org/licenses/by/4.0/. The Creative Commons Public Domain Dedication waiver (http://creativecommons.org/publicdomain/ zero/1.0/) applies to the data made available in this article, unless otherwise stated in a credit line to the data. 
in which predefined dietary patterns based on nutrition guidelines or recommendations are used to measure the level of adherence to these patterns. The second approach is based on a posteriori analysis, using multivariate statistical techniques, such as principal component analysis (PCA) and cluster analysis. These methods are completely exploratory which use all available dietary data to extract dietary patterns based on inter-correlations between food groups or nutrients intakes [7, 8]. Several investigators in the field of nutrition epidemiology have identified various dietary patterns; e.g. Mediterranean, low salt, low carbohydrate, low fat or dietary approach to stop hypertension diet (DASH), each of them has been shown to have differing effects on human health [9]. The DASH diet was related to the greatest overall decrease in the systolic and diastolic blood pressure (SBP, DBP) [10]. The healthy eating index (HEI) is a diet quality measurement which assesses the conformance of food group intakes to the dietary guidelines. Poor diet quality calculated by HEI has been shown to contribute to the development of hypertension [11]. Moreover, unhealthy dietary patterns identified through PCA were associated with higher BP among Kuwaiti and Lebanese adults [12, 13]. Despite the tremendous increase in the prevalence of hypertension in Iran [14], there are no standard quantitative dietary guidelines to evaluate dietary patterns and their relationships with hypertension. Also, to our knowledge, no study has examined adherence to multiple dietary patterns in a prospective study to determine which pattern have high strength associations with the risk of hypertension among a group of Iranian adults. Also, the amount of variance and interpretability of these patterns as an exposure has not been specified. To address this gap, and to help identifying a feasible and effective dietary pattern to prevent and reduce the risk of hypertension in our country, we prospectively investigated the association between a priori and a posteriori derived dietary patterns and incident hypertension among Tehranian adults participated in the Tehran lipid and glucose study (TLGS).

\section{Methods}

\section{Study population}

Participants for this study were recruited from the TLGS, a large-scale population-based cohort study performed to determine risk factors for non-communicable diseases in a representative sample of residents of Tehran, the capital of Iran. At first phase of the study (1999-2001), 15,005 individuals aged $\geq 3$ years were selected using multistage stratified cluster random sampling and follow-up examinations were conducted in five consecutive phases: Phase 2 (2002-2005), Phase 3 (2005-2008), Phase 4 (20082011), Phase 5 (2012-2015) and Phase 6 (2015-2018).
The details of the study have been published elsewhere [15]. Of 8843 individuals aged $\geq 18$ years who participated in Phase 4, a total of 6791 subjects (3016 men) completed the dietary assessment. We selected these subjects as baseline population in this study and followed them at next Phases (Phases 5 and 6). We compared characteristics of adult participants who had dietary data (respondents, $\mathrm{n}=6791$ ) and those who did not have (nonrespondents, $\mathrm{n}=2052$ ). Among respondents, $44.4 \%$ were male, $22.6 \%$ were current smoker and $5.5 \%$ had family history of CVD (FH-CVD), compared with 44.8\%, 20.6\% and $4.7 \%$, respectively, in non-respondents $(\mathrm{P}>0.05)$. The mean (SD) of age and body mass index (BMI) were 40.8 (14.1) and 27.3 (4.9), respectively, in respondents vs. $44.8(17.1)$ and $27.7(5.2)$ in non-respondents $(\mathrm{P}<0.001)$. The mean (SD) of SBP and DBP blood pressure among respondents were 114 (16.7) and 75.5 (11.1), respectively, compared with 118 (19.7) and 77.2 (11.5) $\mathrm{mmHg}$ in nonrespondents $(\mathrm{P}<0.001)$. The level of physical activity did not differ in two groups.

Of 6791 participants, we excluded under- or overreporters of energy intake $(<800$ or $\geq 4200 \mathrm{kcal} /$ day, $\mathrm{n}=457)$, those with hypertension at baseline $(\mathrm{n}=1116)$ and subjects with missing data on hypertension status at baseline $(\mathrm{n}=19)$. Finally, after excluding participants without any follow up data $(\mathrm{n}=406), 4793$ subjects (1986 men) were remained and entered in the analysis.

\section{Measurements}

At baseline and next phases, information on age, sex, smoking status, medical history and medication use was obtained through a personal interview using a standardized questionnaire [15].

\section{Anthropometric and blood pressure measurements}

Bodyweight was measured using a calibrated digital scale (Seca 707). Height was measured using a portable stadiometer. A qualified physician measured BP using a standard mercury sphygmomanometer after the participants remained seated for $15 \mathrm{~min}$. The calibration of sphygmomanometer was done by Iranian Institute of Standards and Industrial Researches. The cuff was placed on the right arm, which was at the heart level and bloated as high rate as possible increments until the cuff pressure was $30 \mathrm{mmHg}$, above the level at which the radial pulse disappeared. Two separate measurements were performed with an at least 30-secondinterval time; the mean of two measurements was recorded as the participant's BP. The SBP was determined as the appearance of the first sound [Korotkoff phase 1], and the DBP was determined as the disappearance of the sound [Korotkoff phase 5] during deflating the cuff at a $2-3 \mathrm{~mm}$ per second decrement rate [15]. 


\section{Physical activity measurements}

The physical activity level (PAL) was assessed using the Persian-translated modifiable activity questionnaire (MAQ) with high reliability and relative validity [16].

\section{Dietary intake assessment}

Dietary data were collected at baseline through faceto-face personal interviews with the use of a valid and reliable 168-items semi-quantitative food frequency questionnaire (FFQ). Participants used the standard serving sizes to report the usual frequency of consumption of individual food items on a daily, weekly, or monthly basis during the last year. The usual food intakes were then converted to daily intake (in grams) and were calculated in energy-adjusted terms (serving per $1000 \mathrm{kcal} /$ day). Because the Iranian food composition table (FCT) is incomplete, the United States Department of Agriculture (USDA) FCT was used to analysis of food composition [17]. Foods listed in the FFQ were collapsed into 20 mutually exclusive food categories based on the similarity of type of food and nutrient composition.

\section{DASH score}

The DASH diet is a dietary pattern originally developed to prevent and control hypertension. DASH score is an index for measuring diet quality [18]. We computed a 40 -points DASH score which includes 8 dietary components [19]. All components were computed per $1000 \mathrm{kcal}$ and were then divided into quintiles. Each quintile intake received 1 point. For fruits, vegetables, whole grains, lowfat dairy, nuts and legumes, a score 5 was given to those in the top quintile. For sodium, red and processed meats, and sweetened beverages, the lowest quintile was given a score of 5 , and the top quintile was given a score of one. The overall DASH score was then obtained by adding the component scores ranging from 8 to 40 . A higher DASH score indicates better adherence.

\section{HEl score}

HEI is based on key recommendations of the 2015-2020 dietary guidelines for Americans (DGA). It is comprised of 13 dietary components. Nine adequacy components include total fruits, whole fruits, total vegetables, greens and beans, whole grains, dairy, total protein foods, seafood and plant proteins, and fatty acids. Four moderation components (those that should be limited) include refined grains, sodium, added sugars, and saturated fats [20]. The HEI scoring is based on density (amount per $1000 \mathrm{kcal}$, ratio of fatty acids) and recommendations are in the range of 1200-2400 kcal dietary intake. To compute the score of HEI, six components from nine adequacy components (total fruit, whole fruit, total vegetables, greens and beans, total protein foods and seafood and plant proteins) each received a score of 0 and 5 respectively for the lowest and highest consumption. The other three adequacy components (whole grains, dairy and fatty acids) were scored from 0 to 10 for the lowest and highest consumption, respectively.

An individual who had an amount of zero per $1000 \mathrm{kcal}$ receive a minimum score of zero; therefore, densities of exactly half the standard for maximum points would interpret to a score of half the possible points (e.g., 5 out of 10 score).

The four moderation components (refined grains, sodium, added sugars, and saturated fats) received a score of 10 and 0 for the lowest and highest intakes, respectively. Intermediate intakes between the minimum and maximum were prorated. The scores from the 13 components were added for a total HEI score ranging from 0 to 100. Higher total HEI scores indicate greater adherence to DGA recommendations [20].

\section{Laboratory assays}

Blood samples were collected after a 12- to 14-h overnight fasting. Fasting plasma glucose (FPG) was measured using an enzymatic colorimetric method with glucose oxidase. Triglyceride (TG) concentrations were assayed with glycerol phosphate oxidase using the enzymatic colorimetric method. Analyses were performed using Pars Azmoon kits (Pars Azmoon Inc., Tehran, Iran) and a Selectra 2 auto-analyser (Vital Scientific, Spankeren, theNetherlands). Inter- and intra-assay coefficients of variation $(\mathrm{CVs})$ were both $<2.2 \%$ for FPG, $0.6 \%$ and $1.6 \%$ for TG, respectively [15].

\section{Definition of terms and outcome}

Smoking status was categorized as smoker (current smokers) versus non-smoker (including past and neversmokers). A current smoker was defined as a person who smokes cigarettes or other smoking implements daily or occasionally. A positive FH-CVD was defined as diagnosis of CVD in a male first degree relative $<55$ or in a female first degree relative $<65$ years. Individuals were considered physically active when they achieved a minimum of at least $600 \mathrm{MET}$ (metabolic equivalent task)minutes per week [21]. Type 2 diabetes mellitus (DM) was defined as $\mathrm{FPG} \geq 7 \mathrm{mmol} / \mathrm{L}$ or $2 \mathrm{~h}-\mathrm{PLPG} \geq 11.1 \mathrm{mmol} / \mathrm{L}$ [22] or using glucose-lowering treatment. Hypertension was defined as a SBP $\geq 140 \mathrm{mmHg}$ or a DBP $\geq 90 \mathrm{mmHg}$ or taking antihypertensive medications [23].

\section{Statistical methods}

Missing data among total population (after applying the exclusion criteria) were $1.1,1.1,0.1,2.4$ and $\% 9.6$ for baseline covariates including smoking status, BMI, TC, 
DM status and PAL, respectively. Thus, multivariate imputations by chained equations (MICE) (mice package in $\mathrm{R}$ software) [24] were used to impute missing values at baseline. The PCA was used as a posteriori method with orthogonal rotation to identify dietary patterns on 20 food groups (as servings per $1000 \mathrm{kcal} /$ day). Eigenvalues $>1$ derived from the correlation matrix, scree plots, factor interpretability and variance explained $>5 \%$ were used to extract key dietary patterns. Food groups with absolute factor loadings values $>0.2$ were considered as contributing highly to the extracted pattern. Each person received a factor score for each dietary pattern by summing intakes of food groups weighted by the loadings generated by the PCA. The posteriori and priori dietary patterns (DASH and HEI) scores were then stratified into quartiles. The baseline characteristics of the study population were compared across quartile categories of each dietary pattern using descriptive analysis. To test linear trend for categorical and continuous variables across quartiles of dietary pattern scores, logistic and linear regression tests were performed respectively; with the use of quartiles of dietary pattern scores as a continuous variable in those models. The incidence density rate of hypertension was calculated by dividing the number of events by the person-years at risk.

The association between different dietary patterns and incidence of hypertension was analyzed using timedependent Cox proportional hazard (Cox $\mathrm{PH})$ regression. The interaction of dietary patterns and age/sex in relation to hypertension were not significant. All covariates (excluding sex and dietary patterns) were included in the models as time-dependent variables. Missing data on time-dependent variables was imputed by the last observation carried forward (LOCF) approach. For these analyses, the lowest quartiles of the different dietary patterns were considered as the reference category. Time to event was defined as the time between baseline and the event date (for event cases) or the last follow-up (for censored cases), whichever occurred first. The event date was defined as the mid-time between the date of the follow-up visit at which hypertension was detected for the first time, and the most recent follow-up visit prior to the diagnosis. Study participants were censored due to death, loss to follow-up or non-occurrence of hypertension before the end of the follow-up (18th April 2018). Two models were developed; model 1 was adjusted for the age and sex. Model 2 was further adjusted for time dependent BMI, smoking, DM status, PAL, TG, FH-CVD, total energy and salt intakes as the most important confounders. The PH assumption was verified using Schoenfeld residuals test and plot of $\log [-\log$ (survival)] versus $\log$ (time) to see if they are parallel. We conducted tests for linear trends with the use of quartiles of dietary patterns as a continuous variable and modeled this variable in separate Cox PH models. Analyses were conducted with $\mathrm{R}$ software (version 3.6.2) and the Statistical Package for Social Sciences (SPSS; version 21.0), and a two sided P values $<0.05$ were considered statistically significant.

\section{Results}

Of 4793 participants, $58.6 \%$ were women, and the mean (SD) age at baseline was 40.3 (13.5) and 37.9 (12.1) years in men and women, respectively. During a median follow-up of 6.3 years (inter-quartile range: 5.7-6.9), 727 incident cases of hypertension (343 in men and 384 in women) occurred. Incidence rate $(95 \%$ confidence interval (CI)) was 27.1 (25.2-29.2), 31.4 (28.2-34.9), and 24.2 (21.9-26.7) per 1000 person years in total population, men and women, respectively.

Two dietary patterns were extracted by PCA; a healthy dietary pattern which was positively associated with the consumption of nuts and seeds, low fat dairy products, vegetables, fruits, poultry and fish; and an unhealthy dietary pattern characterized by foods such as red meat, fast food, high fat dairy products, refined grain, salty snacks, and drinks (Table 1).

Table 1 Factor loadings for two dietary patterns identified by principal component analysis among the participants of the Tehran Lipid and Glucose Study

\begin{tabular}{|c|c|c|}
\hline Food groups & Healthy & Unhealthy \\
\hline Tea and coffee & & 0.24 \\
\hline Sugar sweetened beverages & -0.20 & 0.68 \\
\hline Legumes & & -0.22 \\
\hline Red meats & & 0.28 \\
\hline Nuts and seeds & 0.24 & 0.20 \\
\hline Fast foods & & 0.51 \\
\hline Low fat dairy products & 0.26 & -0.29 \\
\hline High fat dairy products & & 0.21 \\
\hline Green vegetables & 0.61 & \\
\hline Yellow and red vegetables & 0.69 & \\
\hline Other vegetables & 0.72 & \\
\hline Total fruit & 0.43 & \\
\hline Fruit juices & 0.45 & -0.24 \\
\hline Refined grains & -0.61 & 0.29 \\
\hline Whole grains & & -0.30 \\
\hline Salty snacks & & 0.20 \\
\hline Poultry and fish & 0.24 & \\
\hline Added sugars & & 0.69 \\
\hline Liquid oils & 0.37 & 0.22 \\
\hline Solid oils & -0.25 & \\
\hline$\%$ variance & 12.7 & 9.84 \\
\hline
\end{tabular}


The mean score of HEI and DASH were $63.1 \pm 8.92$ and $23.0 \pm 3.80$, respectively. Baseline characteristics of participants across quartiles of each dietary pattern scores are shown in Table 2. Participants in higher quartiles of all dietary patterns except the unhealthy dietary pattern were older, compared to those in the lowest quartile. Also, higher quartiles of the healthy dietary pattern and HEI scores were associated with lower BMI. In addition, higher quartiles of all dietary patterns, except the unhealthy dietary pattern were associated with higher levels of physical activity and lower proportion of current smoker. However, higher quartiles of the healthy dietary pattern and DASH scores were associated with higher proportion of diabetes. Baseline characteristic of participants who developed and did not develop hypertension is shown in Additional file 1: Table S1 by sex. Men and women who developed hypertension had higher mean of age, BMI, TG, SBP and DBP than subjects who did not develop hypertension. Also the prevalence of diabetes and current smoking were higher among those individuals who developed hypertension.
Baseline characteristic of male and female participants by quartiles of priori- and posteriori dietary patterns are shown in Additional file 1: Table S2 and S3.

Baseline dietary intakes of participants who developed and did not develop hypertension are presented in Additional file 1: Table S4. Participants who developed hypertension had higher intakes of added sugar, red meats and low fat dairy intake. Subjects who did not develop hypertension had higher intake of legumes, fast food, carbonated drinks and energy intake.

Dietary intakes of participants across quartiles of all dietary pattern scores are presented in Tables 3 and 4 . Participants in the top quartiles of the healthy dietary pattern, DASH and HEI scores had higher intakes of liquid oil, legumes, nuts and seeds, low fat dairy products, vegetables and total fruit, compared to those in the lowest; however, intakes of solid oil, added sugars, fast food, refined grains, and sweetened drinks tend to decrease across quartiles of these dietary pattern scores. In addition, individuals with higher scores of the unhealthy dietary pattern had higher intakes of solid oil, added sugars, red meats, fast food, high fat dairy products, salty snacks, sweetened drinks, and energy intake.

Table 2 Baseline characteristics of participants by quartiles of posteriori and priori dietary patterns in the participants of the Tehran Lipid and Glucose Study $(n=4793)$

\begin{tabular}{|c|c|c|c|c|c|c|c|c|c|c|}
\hline & \multicolumn{4}{|c|}{ Quartiles of healthy dietary pattern score } & \multirow[t]{2}{*}{$P$ trend } & \multicolumn{4}{|c|}{ Quartiles of unhealthy dietary pattern score } & \multirow[t]{2}{*}{$P$ trend } \\
\hline & 1 & 2 & 3 & 4 & & 1 & 2 & 3 & 4 & \\
\hline$n$ & 1198 & 1198 & 1199 & 1198 & & 1198 & 1198 & 1199 & 1198 & \\
\hline Age (years) & $36.5(12.5)$ & $37.6(12.8)$ & $39.4(12.6)$ & $42.1(12.5)$ & $<0.001$ & $43.4(13.1)$ & $40.1(12.8)$ & $37.0(12.0)$ & $35.1(11.7)$ & $<0.001$ \\
\hline BMI $\left(\mathrm{kg} / \mathrm{m}^{2}\right)$ & $27.7(4.7)$ & $26.7(4.2)$ & $26.2(4.4)$ & $26.2(4.4)$ & $<0.001$ & $26.1(4.6)$ & $26.9(4.5)$ & $26.7(4.7)$ & $26.0(4.4)$ & 0.810 \\
\hline TG $(\mathrm{mmol} / \mathrm{L})$ & $1.51(0.93)$ & $1.47(1.45)$ & $1.46(0.88)$ & $1.53(0.94)$ & 0.66 & $1.43(0.8)$ & $1.45(1.0)$ & $1.54(1.4)$ & $1.56(0.91)$ & 0.017 \\
\hline SBP (mmHg) & $108(11.6)$ & $108(11.8)$ & $108(12.2)$ & $108(11.8)$ & 0.713 & $104(12.5)$ & 109(11.8) & $108(11.5)$ & $107(11.5)$ & 0.001 \\
\hline $\mathrm{DBP}(\mathrm{mmHg})$ & $75.0(8.2)$ & $73.12(8.7)$ & $73.18(8.3)$ & $72.5(8.45)$ & 0.310 & $73.1(8.4)$ & $73.1(8.6)$ & $72.8(8.4)$ & $72.7(8.4)$ & 0.412 \\
\hline Low PAL (\%) & 75.6 & 73.2 & 70.8 & 64.9 & $<0.001$ & 69.9 & 70.8 & 71.6 & 72.3 & 0.621 \\
\hline FH-CVD (\%) & 4.8 & 4.4 & 5.6 & 6.3 & 0.170 & 4.8 & 5.2 & 5.4 & 5.6 & 0.854 \\
\hline Diabetes (\%) & 4.8 & 3.9 & 5.0 & 7.9 & $<0.001$ & 9.1 & 5.8 & 4.2 & 2.5 & $<0.001$ \\
\hline \multirow[t]{3}{*}{ Current smoker (\%) } & 30 & 25.4 & 19.8 & 13.9 & $<0.001$ & 14.6 & 17.0 & 24.4 & 35.1 & $<0.001$ \\
\hline & \multicolumn{4}{|c|}{ Quartile of DASH score } & $P$ trend & \multicolumn{4}{|c|}{ Quartile of HEI-2015 score } & $P$ trend \\
\hline & 1 & 2 & 3 & 4 & & 1 & 2 & 3 & 4 & \\
\hline$n$ & 1254 & 932 & 1328 & 1279 & & 1212 & 1231 & 1183 & 1167 & \\
\hline Age (years) & $34.1(11.46)$ & $37.5(11.9)$ & $39.6(12.5)$ & $44.1(12.9)$ & $<0.001$ & $36.9(12.1)$ & $37.7(12.4)$ & $39.3(12.8)$ & $41.9(13.2)$ & $<0.001$ \\
\hline BMI $\left(\mathrm{kg} / \mathrm{m}^{2}\right)$ & $26.0(4.6)$ & $26.4(4.5)$ & $26.7(4.4)$ & $27.5(4.51)$ & $<0.001$ & $27.4(4.5)$ & $26.5(4.5)$ & $26.4(4.5)$ & $26.3(4.6)$ & $<0.001$ \\
\hline TG $(\mathrm{mmol} / \mathrm{L})$ & $1.40(0.8)$ & $1.49(0.9)$ & $1.52(1.4)$ & $1.53(0.93)$ & 0.007 & $1.40(0.85)$ & $1.51(1.47)$ & $1.49(0.89)$ & $1.52(1.01)$ & 0.84 \\
\hline $\mathrm{SBP}(\mathrm{mmHg})$ & $109(12.0)$ & $108(11.6)$ & $109(12.0)$ & $107(11.7)$ & $<0.001$ & $109(11.8)$ & $108(11.9)$ & $108(12.0)$ & $107(11.7)$ & $<0.001$ \\
\hline $\mathrm{DBP}(\mathrm{mmHg})$ & $72.5(8.5)$ & $72.9(8.64)$ & $73.1(8.52)$ & $73.2(8.2)$ & 0.742 & $73.01(8.5)$ & $72.6(8.5)$ & $72.8(8.5)$ & $73.3(8.2)$ & 0.120 \\
\hline Low PAL (\%) & 75.2 & 74.5 & 71.5 & 64.3 & $<0.001$ & 76.3 & 72.9 & 68.8 & 66.3 & $<0.001$ \\
\hline FH-CVD (\%) & 6.2 & 5.8 & 5.6 & 5.3 & 0.612 & 6.2 & 5.3 & 4.9 & 4.6 & 0.342 \\
\hline Diabetes (\%) & 3.3 & 5.0 & 5.4 & 7.7 & $<0.001$ & 3.7 & 4.8 & 4.4 & 3.9 & 0.654 \\
\hline Current smoker (\%) & 32.5 & 25.8 & 19.3 & 13.4 & $<0.001$ & 26.6 & 24.0 & 22.1 & 16.2 & $<0.001$ \\
\hline
\end{tabular}


Table 3 Dietary intakes of participants by quartiles of posteriori dietary patterns in the participants of the Tehran Lipid and Glucose Study $(n=4793)$

\begin{tabular}{|c|c|c|c|c|c|c|c|c|c|c|}
\hline \multirow[b]{3}{*}{$\mathbf{n}$} & \multicolumn{4}{|c|}{ Quartiles of healthy dietary pattern score } & \multirow[t]{2}{*}{$P$ trend } & \multicolumn{4}{|c|}{ Quartiles of unhealthy dietary pattern score } & \multirow[t]{3}{*}{$P$ trend } \\
\hline & 1 & 2 & 3 & 4 & & 1 & 2 & 3 & 4 & \\
\hline & 1198 & 1198 & 1199 & 1198 & & 1198 & 1198 & 1199 & 1198 & \\
\hline \multicolumn{11}{|l|}{ Dietary intakes } \\
\hline Liquid oils (gr/1000 kcal) & $2.83(2.0)$ & $3.68(2.4)$ & $4.35(2.8)$ & $5.54(4.1)$ & $<0.001$ & $3.24(2.2)$ & $3.90(2.5)$ & $4.33(3.0)$ & $4.93(4.1)$ & 0.104 \\
\hline Solid oils (gr/1000 kcal) & $7.91(7.1)$ & $6.26(5.6)$ & $5.29(5.2)$ & $3.88(4.7)$ & $<0.001$ & $4.82(5.6)$ & $5.97(6.0)$ & $6.28(6.1)$ & $6.27(5.8)$ & $<0.001$ \\
\hline Added sugars (\% of energy) & $5.39(3.4)$ & $5.45(3.3)$ & $5.07(2.9)$ & $4.24(2.6)$ & $<0.001$ & $2.71(1.4)$ & $4.01(1.8)$ & $5.36(2.2)$ & 8.07 (3.6) & $<0.001$ \\
\hline Legumes $^{\mathrm{a}}$ & $0.15(0.1)$ & $0.18(0.1)$ & $0.20(0.1)$ & $0.22(0.2)$ & $<0.001$ & $0.24(0.2)$ & $0.19(0.1)$ & $0.18(0.1)$ & $0.15(0.1)$ & $<0.001$ \\
\hline Red meats $^{\mathrm{a}}$ & $0.32(0.2)$ & $0.37(0.2)$ & $0.41(0.3)$ & $0.41(0.3)$ & $<0.001$ & $0.28(0.1)$ & $0.35(0.2)$ & $0.41(0.2)$ & $0.48(0.3)$ & $<0.001$ \\
\hline Nuts and seeds ${ }^{a}$ & $0.13(0.2)$ & $0.18(0.2)$ & $0.22(0.3)$ & $0.29(0.4)$ & $<0.001$ & $0.14(0.1)$ & $0.20(0.2)$ & $0.22(0.3)$ & $0.28(0.4)$ & $<0.001$ \\
\hline Fast foods ${ }^{\mathrm{a}}$ & $0.16(0.2)$ & $0.18(0.2)$ & $0.17(0.1)$ & $0.14(0.1)$ & 0.004 & $0.07(0.07)$ & $0.12(0.0)$ & $0.17(0.1)$ & $0.28(0.2)$ & $<0.001$ \\
\hline Low fat dairy products ${ }^{\mathrm{a}}$ & $0.49(0.3)$ & $0.58(0.4)$ & $0.62(0.3)$ & $0.73(0.4)$ & $<0.001$ & $0.77(0.4)$ & $0.62(0.3)$ & $0.57(0.3)$ & $0.46(0.3)$ & $<0.001$ \\
\hline High fat dairy products ${ }^{\mathrm{a}}$ & $0.31(0.3)$ & $0.34(0.3)$ & $0.35(0.3)$ & $0.32(0.3)$ & 0.39 & $0.21(0.2)$ & $0.33(0.3)$ & $0.37(0.3)$ & $0.39(0.3)$ & $<0.001$ \\
\hline Green vegetables $^{\mathrm{a}}$ & $0.14(0.1)$ & $0.21(0.1)$ & $0.29(0.2)$ & $0.43(0.3)$ & $<0.001$ & $0.29(0.2)$ & $0.29(0.2)$ & $0.27(0.2)$ & $0.23(0.1)$ & $<0.001$ \\
\hline Yellow and red vegetables ${ }^{\mathrm{a}}$ & $0.15(0.1)$ & $0.24(0.1)$ & $0.32(0.2)$ & $0.53(0.3)$ & $<0.001$ & $0.36(0.3)$ & $0.32(0.2)$ & $0.30(0.2)$ & $0.25(0.2)$ & $<0.001$ \\
\hline Other vegetables ${ }^{\mathrm{a}}$ & $0.38(0.1)$ & $0.55(0.2)$ & $0.74(0.3)$ & $1.08(0.5)$ & $<0.001$ & $0.75(0.5)$ & $0.72(0.4)$ & $0.69(0.4)$ & $0.60(0.4)$ & $<0.001$ \\
\hline Refined grains ${ }^{a}$ & $5.62(1.6)$ & $4.19(1.3)$ & $3.56(1.2)$ & $2.74(1.2)$ & $<0.001$ & $4.68(2.03)$ & $4.17(1.6)$ & $3.76(1.5)$ & $3.49(1.3)$ & $<0.001$ \\
\hline Whole grains ${ }^{\mathrm{a}}$ & $0.75(1.0)$ & $0.83(1.1)$ & $0.78(0.98)$ & $0.78(0.9)$ & 0.42 & $1.28(1.4)$ & $0.78(0.9)$ & $0.59(0.69)$ & $0.49(0.5)$ & $<0.001$ \\
\hline Salty snacks ${ }^{\mathrm{a}}$ & $0.11(0.1)$ & $0.13(0.1)$ & $0.14(0.3)$ & $0.13(0.2)$ & $<0.001$ & $0.08(0.1)$ & $0.11(0.1)$ & $0.14(0.1)$ & $0.18(0.4)$ & $<0.001$ \\
\hline Poultry and fish ${ }^{\mathrm{a}}$ & $0.45(0.3)$ & $0.56(0.4)$ & $0.64(0.5)$ & $0.76(0.7)$ & $<0.001$ & $0.53(0.4)$ & $0.59(0.5)$ & $0.64(0.6)$ & $0.65(0.6)$ & 0.276 \\
\hline Tea and coffee (gr/day) & $559(461)$ & $577(434)$ & $599(434)$ & $599(463)$ & 0.006 & $443(323)$ & $523(366)$ & $606(444)$ & $733(586)$ & $<0.001$ \\
\hline Carbonated drinks (gr/day) & $62.5(85.9)$ & $53.8(70.1)$ & $42.6(59.0)$ & $29.6(46.2)$ & $<0.001$ & $12.3(14.7)$ & $22.4(24.9)$ & $40.9(41.2)$ & $113(99.5)$ & $<0.001$ \\
\hline Total fruit ${ }^{\mathrm{a}}$ & $0.70(0.5)$ & $1.07(0.7)$ & $1.30(0.8)$ & $1.62(0.9)$ & $<0.001$ & $1.10(0.8)$ & $1.23(0.8)$ & $1.23(0.9)$ & $1.11(0.8)$ & 0.73 \\
\hline Fruits juice* & $0.07(0.1)$ & $0.11(0.2)$ & $0.13(0.2)$ & $0.15(0.2)$ & $<0.001$ & $0.08(0.1)$ & $0.11(0.16)$ & $0.12(0.18)$ & $0.14(0.19)$ & $<0.001$ \\
\hline Salt (gr/1000 kcal) & $2.46(2.0)$ & $2.91(2.0)$ & $2.71(2.1)$ & $2.71(2.0)$ & 0.18 & $2.39(1.8)$ & $2.53(1.8)$ & $2.96(1.9)$ & $2.90(2.3)$ & $<0.001$ \\
\hline Total energy (kcal/day) & $2473(722)$ & $2445(712)$ & $2378(694)$ & $2295(718)$ & $<0.001$ & $2282(698)$ & $2323(709)$ & $2416(706)$ & $2570(713)$ & $<0.001$ \\
\hline
\end{tabular}

$\mathrm{P}$ trend was calculated by treating quartiles of food groups and energy intake as a continuous variable in the linear regression model. Values are reported as mean (SD)

a Servings per $1000 \mathrm{kcal}$

Dietary intakes of participants by quartiles of prioriand posteriori dietary patterns among male participants are shown in Additional file 1: Tables S5 and S6.

Dietary intakes of participants by quartiles of extracted dietary patterns by PCA and priori dietary patterns among female participants are shown in Additional file 1: Tables S7 and S8.

The multivariable-adjusted HRs for the risk of hypertension across quartiles of dietary pattern scores are shown in Table 5.

Participants in the highest quartile of HEI score had a 23\% (HR: 1.23; 95\% CI: 1.00-1.53; P trend: 0.056) increased risk of hypertension, compared with individuals in the lowest quartile. However, the association was attenuated (1.19;0.96-1.48) and became non-significant after further adjustment for confounders (P trend: 0.082). Increasing DASH score and the healthy dietary pattern were not associated with reduced risk of hypertension. Further, no significant association was observed between the unhealthy dietary pattern and incidence of hypertension.

\section{Discussion}

According to the results of this large prospective cohort study, adherence to the posteriori-derived dietary patterns (healthy and unhealthy dietary pattern) and the priori dietary patterns (HEI and DASH) was not associated with the risk of hypertension after adjustment for confounding factors. Participants in the highest quartile of HEI score had a $23 \%$ increased risk of hypertension compared to individuals in the lowest quartile; however, this association became non-significant after further adjustment for confounding factors.

Generally, we did not find a significant relationship between the derived healthy dietary pattern and risk of hypertension. Although the posteriori dietary patterns in our study cannot be compared directly with those of other studies, anon-significant relationship between the 


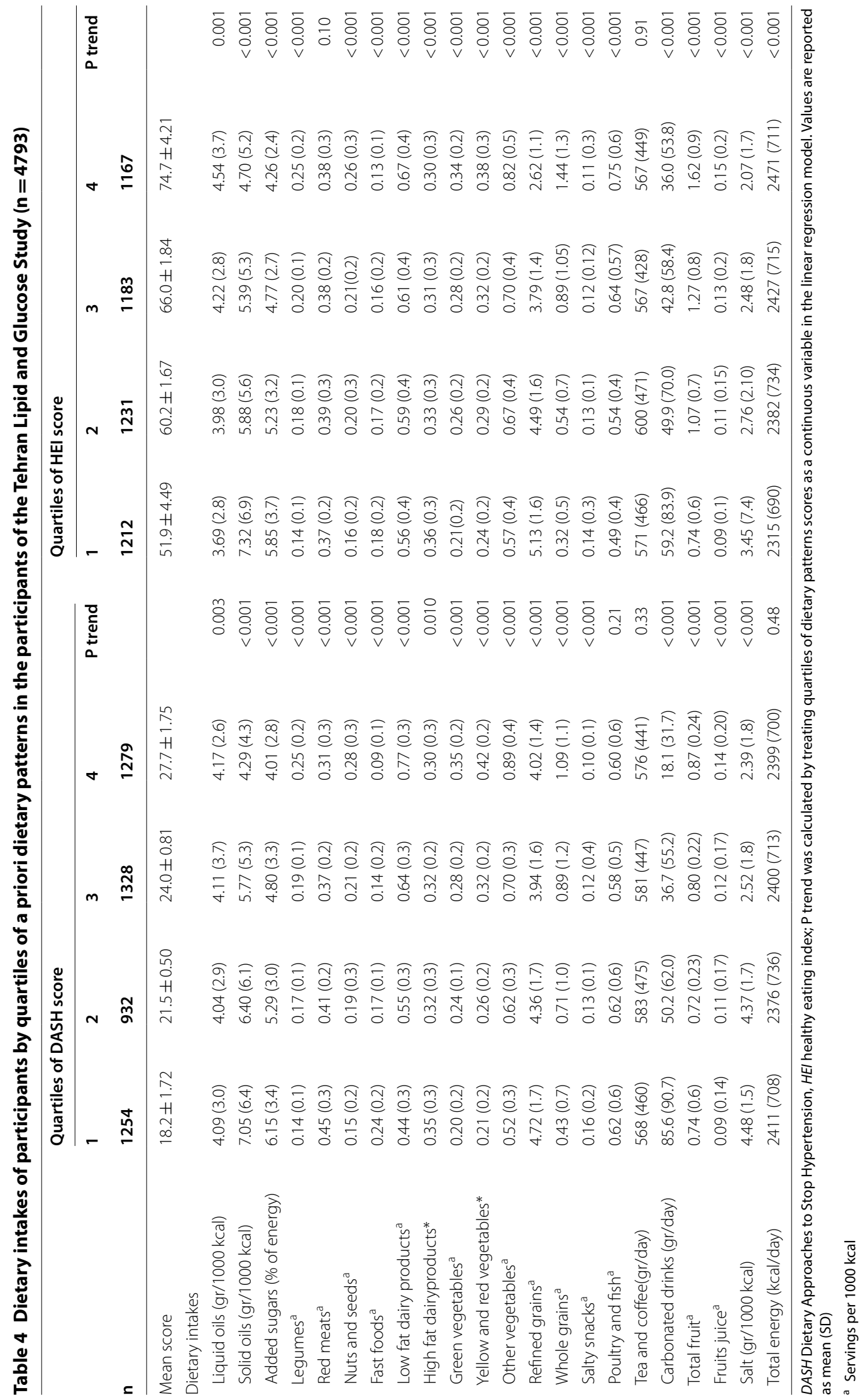


Table 5 Hazard ratios of hypertension in relation to quartiles of different dietary patterns in the participants of the Tehran Lipid and Glucose Study $(n=4793)$

\begin{tabular}{|c|c|c|c|c|c|}
\hline & \multicolumn{4}{|c|}{ Quartiles of dietary patterns } & \multirow[t]{2}{*}{$P$ trend } \\
\hline & Q1 & Q2 & Q3 & Q4 & \\
\hline \multicolumn{6}{|l|}{ Healthy } \\
\hline Incident hypertension/ Number at baseline & $160 / 1198$ & $166 / 1198$ & 189/1199 & 212/1198 & \\
\hline Model 1 & Reference & $0.94(0.76-1.17)$ & $1.02(0.82-1.26)$ & $1.13(0.91-1.39)$ & 0.166 \\
\hline Model 2 & Reference & $0.93(0.75-1.16)$ & $0.97(0.77-1.21)$ & $1.15(0.90-1.47)$ & 0.231 \\
\hline \multicolumn{6}{|l|}{ Unhealthy } \\
\hline Incident hypertension/ Number at baseline & 226/1198 & 204/1198 & 154/1199 & $143 / 1198$ & \\
\hline Model 1 & Reference & $1.10(0.91-1.34)$ & $0.92(0.74-1.14)$ & $1.04(0.83-1.30)$ & 0.854 \\
\hline Model 2 & Reference & $1.11(0.91-1.34)$ & $0.94(0.76-1.18)$ & $1.01(0.77-1.33)$ & 0.795 \\
\hline \multicolumn{6}{|l|}{ DASH } \\
\hline Incident hypertension/ Number at baseline & $129 / 1254$ & $135 / 932$ & $211 / 1328$ & $252 / 1279$ & \\
\hline Model 1 & Reference & $1.20(0.94-1.54)$ & $1.18(0.94-1.48)$ & $1.19(0.96-1.49)$ & 0.168 \\
\hline Model 2 & Reference & $1.18(0.93-1.51)$ & $1.12(0.89-1.41)$ & $1.19(0.95-1.49)$ & 0.197 \\
\hline \multicolumn{6}{|l|}{$\mathrm{HEl}$} \\
\hline Incident hypertension/ Number at baseline & $149 / 1212$ & $173 / 1231$ & $184 / 1183$ & $221 / 1167$ & \\
\hline Model 1 & Reference & $1.10(0.88-1.38)$ & $1.12(0.90-1.40)$ & $1.23(1.00-1.53)^{*}$ & 0.056 \\
\hline Model 2 & Reference & $1.07(0.86-1.33)$ & $1.13(0.91-1.41)$ & $1.19(0.96-1.48)$ & 0.082 \\
\hline
\end{tabular}

Model 1: Adjusted for age and sex

Model 2: Adjusted for age, sex, and time dependent body mass index, smoking status, diabetes status, physical activity, triglycerides, family history of cardiovascular disease, salt and total energy intake

For the test for trend, we treated quartiles of dietary patterns scores as a continuous variable and modeled this variable in the Cox regression analyses

DASH Dietary Approaches to Stop Hypertension, HEI healthy eating index

healthy dietary pattern and risk of hypertension has also been reported in several studies $[5,25]$, which was consistent with our findings. However, the pooled results from a meta-analysis indicated that empirically derived healthy dietary pattern was associated with a decreased odds of hypertension [3]. Lack of association between the healthy dietary pattern and hypertension in our study may be due to the interactions among different food groups. For example, in our study higher adherence to the healthy dietary pattern were characterized by higher intakes of healthy food groups and higher consumption of some unhealthy food groups such as salty snacks and red meats, which may nullify the benefits of the healthy food groups. Moreover, whole grains with anti-inflammatory and antioxidant effects which could reduce vascular oxidative stress, endothelial impairment, arterial stiffness, and lower BP [26, 27], was not associated with higher healthy dietary pattern score (Table 3). Previous studies have shown that each additional daily $100 \mathrm{~g}$ intake of red meat was associated with 14\% increased risk of hypertension. This may be due to Millard reaction products in cooked meat through its inflammatory and oxidation pathways [28]. Also, evidence from observational studies has reported strong positive association between daily sodium intake and BP [29]. Furthermore, lack of association may be due to the cooking methods or added fats which could contribute toward the neutralizing the beneficial effects of healthy foods [30]. Finally, participants in the higher quartiles of healthy dietary pattern scores were older and had higher prevalence of diabetes than their counterparts in the lowest quartiles; which are two important factors for increasing hypertension; a finding that was also observed in Asghari et al. study [31].

In our study, the overall risk increment observed with higher HEI score in the crude model which attenuated after adjustment for energy intake. This unexpected result may be due to this fact that HEI assess diet quality independent of diet quantity; it evaluates density rather than absolute amounts, so the interpretation of HEI score depends on whether a person has achieved energy balance. Also, HEI score evaluates merged of foods which collectively reveal a pattern with a single aspect of diet quality; indeed the patterns of diet quality can be different in each person and additional information enclosed in the pattern rather than overall score should be pointed $[32,33]$.

The unhealthy dietary pattern was not associated with the incidence of hypertension in our study which was inconsistent with Monge A. et al. study in Mexican 
women [34] and Park JE et al. study in Korean adults [35]; however our results were consistent with previous metaanalysis study in which western-style or unhealthy dietary pattern was not related to the risk of hypertension [3]. This may be due to some food groups like high-fat dairy products and nuts which contain calcium, potassium and other vitamins in combination with unhealthy foods that counteract with the harmful effect of unhealthy style pattern and change this relationship to non-significant [3].

Based on our results, DASH eating pattern, a diet rich in fruit and vegetable, had no relationship with incidence of hypertension. This finding contrasts with the findings of previous clinical trial studies that demonstrated the influence of DASH diet on decreasing SBP $[36,37]$. In two randomized clinical trials (RCT), the DASH diet had beneficial effects on decreasing BP among diabetic patients [37] and individuals with the metabolic syndrome [38]. Four points can be noted in our findings to justify this difference. First, we computed DASH score by scoring quintiles of intakes of the eight main components; it is possible that the average of each food group intakes in the top quintile of our study was inconsistent with other studies. Also based on rankings of dietary intake score, individuals who are in the fourth quartile intake for each food group might not meet the current recommendations of that food group. Second, metaanalysis of RCT studies reported that DASH diet can be more effective in hypertensive persons than in normotensive people $[29,36]$; and third, the beneficial effect of a DASH diet on BP depends on its ability to restrict calorie intake and weight loss [29,36]; however, in our study, energy intake increased with higher adherence to DASH diet. Fourth, the applied DASH eating pattern was not homogeneous in different studies, and the characteristic of DASH diet in our study may differ from other studies due to diversity of food groups eaten in different countries [39]. Considering the above mentioned issues, it may be more effective to score dietary patterns based on recommended amount of local food groups to reduce the population risk effectively [39].

In our study, none of the overall eating patterns obtained by the posteriori or priori approach had significant association with increased risk of hypertension, suggesting the need to adapt or develop a score that tailors to local diets. On the other hand, hypertension is a complex concept and has multidimensional aspects being affected by multiple unknown or unmeasured lifestyle factors that are not accounted for analyzing the relationship of dietary patterns and hypertension in our study. Furthermore, we did not include genetic factors which have an important role in the development of hypertension [40]. It is suggested to consider the interaction of various genetic markers and lifestyle factors such as diet in determining hypertension in future studies. Finally, categorizing study samples by quartiles of dietary pattern scores may affect statistical power in the HR context; as the statistical power of our study to detect a HR of 20 and $30 \%$ were about 41 and $71 \%$ in last quartile of all dietary pattern scores.

To our knowledge, this is the first prospective study to examine the relation of two kinds of dietary patterns (a priori and a posterior dietary pattern) and incidence of hypertension in the Middle East. Strengths of our study include cohort design and detailed information on physical activity, BMI, smoking status, diabetes status and lipid profile, which allowed extensive adjustment for hypertension risk factors. Certain limitations of this study need to be considered. First, the small number of incident events precluded stratification of analyses by sex. Second, this study was performed on residents of district 13 of Tehran that may not necessarily be representative of the general Iranian populations. Third, as inherent to any dietary pattern analysis study, we assessed dietary patterns at baseline; however, dietary patterns may change over time, leading to biased estimated hazard ratios towards the null. Fourth, statistical methods used to define posteriori-dietary pattern, i.e., PCA, are somewhat subjective and dietary patterns can vary by socioeconomic status, ethnic groups and cultures. Also, we did not have enough information about family income; therefore, in our study, it was not possible to investigate the effect of family income on dietary patterns. For future studies, it is recommended to expand this research with larger sample sizes and a wide range of confounders in other populations of Iranian adults.

\section{Conclusions}

Our study showed no association between priori and posteriori-derived dietary patterns and risk of incident hypertension in this population. These results are of considerable public health importance for promoting local dietary guidelines and new index scores to monitor the quality of food consumption in individuals and population groups, especially in our country with high prevalence of hypertension.

\section{Supplementary Information}

The online version contains supplementary material available at https://doi. org/10.1186/s12967-021-02704-w.

Additional file 1: Table S1. Baseline characteristics of participants who developed and did not develop hypertension in the participants of the Tehran Lipid and Glucose Study $(n=4793)$. Table S2. Baseline characteristics of male participants by quartiles of different dietary patterns in the Tehran Lipid and Glucose Study $(n=1986)$. Table S3. Baseline characteristics of female participants by quartiles of different dietary patterns in the Tehran Lipid and Glucose Study $(n=2807)$. Table S4. Baseline dietary 
intake of participants who developed and did not develop hypertension in the Tehran Lipid and Glucose Study $(n=4793)$. Table S5. Dietary intakes of participants by quartiles of extracted dietary patterns by PCA among male participants of the Tehran Lipid and Glucose Study ( $n=1986)$. Table S6. Dietary intakes of participants by quartiles of a priori dietary patterns among male participants of the Tehran Lipid and Glucose Study $(n=1986)$. Table S7. Dietary intakes of participants by quartiles of extracted dietary patterns by PCA among female participants of the Tehran Lipid and Glucose Study ( $n=2807)$. Table S8. Dietary intakes of participants by quartiles of a priori dietary patterns among female participants of the Tehran Lipid and Glucose Study $(n=2807)$.

\section{Abbreviations}

2-h PLPG: 2-H post load plasma glucose; BMI: Body mass index; CVD: Cardiovascular disease; DASH: Dietary approach to stop hypertension; DBP: Diastolic blood pressure; DGA: Dietary guidelines for Americans; DM: Diabetes mellitus; FCT: Food composition table; FFQ: Food frequency questionnaire; FH-CVD: Family history of cardiovascular disease; FPG: Fasting plasma glucose; HEl: Healthy eating index; LOCF: Last observation carried forward; MAQ: Metabolic activity equivalent; MICE: Multivariate imputations by chained equations; PAL: Physical activity level; PCA: Principal component analysis; PH: Proportional hazard; RCT: Randomized clinical trials; SBP: Systolic blood pressure; TLGS: Tehran lipid and glucose study; USDA: United state department of agriculture.

\section{Acknowledgements}

The authors would like to thank the participants and the TLGS personnel for their collaboration.

\section{Authors' contributions}

Conceptualization, AR, FHE and FH; Formal analysis, FHE and AR; Methodology, $\mathrm{AR}$, FH and FHE; Supervision, FA and PM; Writing original draft, AR and FHE; Writing review and editing, FH and PM. All authors read and approved the final manuscript.

\section{Funding}

This study was supported by Research Institute for Endocrine Sciences, Shahid Beheshti University of Medical Sciences, Tehran, Iran.

\section{Availability of data and materials}

The datasets used and/or analyzed during the current study are available from the corresponding author on reasonable request.

\section{Ethics approval and consent to participate}

Ethical approval for this study was obtained from the ethics committee of the Research Institute for Endocrine Sciences, Shahid Beheshti University of Medical Sciences, Tehran, Iran. All participants provided written informed consent before participating in this study.

\section{Consent for publication}

Not applicable.

\section{Competing interests}

The authors declare that they have no competing interests.

\section{Author details}

1 Prevention of Metabolic Disorders Research Center, Research Institute for Endocrine Sciences, Shahid Beheshti University of Medical Sciences, Tehran, Iran. ${ }^{2}$ Nutrition and Endocrine Research Center, Research Institute for Endocrine Sciences, Shahid Beheshti University of Medical Sciences, Tehran, Iran. ${ }^{3}$ Endocrine Research Center, Research Institute for Endocrine Sciences, Shahid Beheshti University of Medical Sciences, Tehran, Iran.

Received: 19 July 2020 Accepted: 11 January 2021

Published online: 25 January 2021

\section{References}

1. Zhou B, Bentham J, Di Cesare M, Bixby H, Danaei G, Cowan MJ, et al. Worldwide trends in blood pressure from 1975 to 2015: a pooled analysis of 1479 population-based measurement studies with 19. 1 million participants. Lancet. 2017;389(10064):37-55.

2. Bromfield S, Muntner P. High blood pressure: the leading global burden of disease risk factor and the need for worldwide prevention programs. Curr Hypertens Rep. 2013;15(3):134-6.

3. Wang C-J, Shen Y-X, Liu Y. Empirically derived dietary patterns and hypertension likelihood: a meta-analysis. Kidney Blood Pressure Res. 2016;41(5):570-81.

4. Padmanabhan S, Delles C, Dominiczak AF. Genetic factors in hypertension. Archives Med Sci Special Issues. 2009;2009(2):219.

5. Monge A, Lajous M, Ortiz-Panozo E, Rodríguez BL, Góngora JJ, LópezRidaura R. Western and Modern Mexican dietary patterns are directly associated with incident hypertension in Mexican women: a prospective follow-up study. Nutr J. 2018;17(1):21.

6. Jacques PF, Tucker KL. Are dietary patterns useful for understanding the role of diet in chronic disease? : Oxford University Press; 2001.

7. Hu FB. Dietary pattern analysis: a new direction in nutritional epidemiology. Curr Opin Lipidol. 2002;13(1):3-9.

8. Panagiotakos D. a-Priori versus a-posterior methods in dietary pattern analysis: a review in nutrition epidemiology. Nutrition bulletin. 2008:33(4):311-5.

9. Kourlaba G, Panagiotakos DB. Dietary quality indices and human health: a review. Maturitas. 2009;62(1):1-8.

10. Sukhato K, Akksilp K, Dellow A, Vathesatogkit P, Anothaisintawee T. Efficacy of different dietary patterns on lowering of blood pressure level: an umbrella review. The American journal of clinical nutrition. 2020.

11. Fanelli SM, Jonnalagadda SS. Poorer Diet Quality Observed Among US Adults With a Greater Number of Clinical Chronic Disease Risk Factors. 2020;11:2150132720945898.

12. Naja F, Itani L, Hwalla N, Sibai AM, Kharroubi SA. Identification of dietary patterns associated with elevated blood pressure among Lebanese men: A comparison of principal component analysis with reduced rank regression and partial least square methods. PLoS ONE. 2019;14(8):e0220942.

13. Al-Lahou B, Ausman LM, Peñalvo JL, Huggins GS, Al-Hooti S, Al-Zenki $\mathrm{S}$, et al. Dietary Patterns Associated with the Prevalence of Cardiovascular Disease Risk Factors in Kuwaiti Adults. J Acad Nutr Diet. 2020;120(3):424-36.

14. Asgari S, Khaloo P, Khalili D, Azizi F, Hadaegh F. Status of Hypertension in Tehran: Potential impact of the ACC/AHA 2017 and JNC7 Guidelines, 2012-2015. Scientific Rep. 2019;9(1):6382.

15. Azizi F, Ghanbarian A, Momenan AA, Hadaegh F, Mirmiran P, Hedayati $M$, et al. Prevention of non-communicable disease in a population in nutrition transition: Tehran Lipid and Glucose Study phase II. Trials. 2009;10(1):5

16. Momenan AA, Delshad M, Sarbazi N, Rezaei Ghaleh N, Ghanbarian A, Azizi F. Reliability and validity of the Modifiable Activity Questionnaire (MAQ) in an Iranian urban adult population. Arch Iran Med. 2012;15(5):279-82.

17. Hosseini-Esfahani F, Jessri M, Mirmiran P, Bastan S, Azizi F. Adherence to dietary recommendations and risk of metabolic syndrome: Tehran Lipid and Glucose Study. Metabolism. 2010;59(12):1833-42.

18. Sacks FM, Obarzanek E, Windhauser MM, Svetkey LP, Vollmer WM, McCullough M, et al. Rationale and design of the Dietary Approaches to Stop Hypertension trial (DASH): a multicenter controlled-feeding study of dietary patterns to lower blood pressure. Ann Epidemiol. 1995;5(2):108-18.

19. Fung TT, Chiuve SE, McCullough ML, Rexrode KM, Logroscino G, Hu FB. Adherence to a DASH-style diet and risk of coronary heart disease and stroke in women. Arch Intern Med. 2008;168(7):713-20.

20. Reedy J, Lerman JL, Krebs-Smith SM, Kirkpatrick SI, Pannucci TE, Wilson MM, et al. Evaluation of the Healthy Eating Index-2015. J Academy Nutrition Dietetics. 2018;118(9):1622-33.

21. Jeon CY, Lokken RP, Hu FB, Van Dam RM. Physical activity of moderate intensity and risk of type 2 diabetes: a systematic review. Diabetes Care. 2007;30(3):744-52.

22. Association AD. Classification and Diagnosis of Diabetes: Standards of Medical Care in Diabetes-2020. Diabetes Care. 2020;43(Suppl 1):S14-31. 
23. Bakris G, Ali W, Parati G. ACC/AHA Versus ESC/ESH on Hypertension Guidelines: JACC Guideline Comparison. J Am Coll Cardiol. 2019;73(23):3018-26

24. Buuren Sv, Groothuis-Oudshoorn K. mice: Multivariate imputation by chained equations in R. Journal of statistical software. 2010:1-68.

25. Shi Z, Papier K, Yiengprugsawan V, Kelly M, Seubsman SA, Sleigh AC. Dietary patterns associated with hypertension risk among adults in Thailand: 8-year findings from the Thai Cohort Study. Public Health Nutrition. 2019;22(2):307-13.

26. de Munter JS, Hu FB, Spiegelman D, Franz M, van Dam RM. Whole grain, bran, and germ intake and risk of type 2 diabetes: a prospective cohort study and systematic review. PLoS Med. 2007;4(8):e261.

27. Wang L, Gaziano JM, Liu S, Manson JE, Buring JE, Sesso HD. Whole- and refined-grain intakes and the risk of hypertension in women. Am J Clin Nutri. 2007;86(2):472-9.

28. Schwingshackl L, Schwedhelm C, Hoffmann G, Knüppel S, labal K, Andriolo $V$, et al. Food groups and risk of hypertension: a systematic review and dose-response meta-analysis of prospective studies. Adv Nutrition. 2017:8(6):793-803.

29. Ozemek C, Laddu DR, Arena R, Lavie CJ. The role of diet for prevention and management of hypertension. Curr Opin Cardiol. 2018;33(4):388-93.

30. Soltani S, Moslehi N, Hosseini-Esfahani F, Vafa M. The Association Between Empirical Dietary Inflammatory Pattern and Metabolic Phenotypes in Overweight/Obese Adults. Int J Endocrinol Metab. 2018;16(2):e60048.

31. Asghari G, Yuzbashian E, Mirmiran P, Azizi F. The association between Dietary Approaches to Stop Hypertension and incidence of chronic kidney disease in adults: the Tehran Lipid and Glucose Study. Nephrology, dialysis, transplantation : official publication of the European Dialysis and Transplant Association - European Renal Association. 2017;32(suppl_2):ii224-ii30.

32. Guenther PM, Kirkpatrick SI, Reedy J, Krebs-Smith SM, Buckman DW, Dodd KW, et al. The Healthy Eating Index-2010 is a valid and reliable measure of diet quality according to the 2010 Dietary Guidelines for Americans. J Nutr. 2014;144(3):399-407.
33. Krebs-Smith SM, Pannucci TE, Subar AF, Kirkpatrick SI, Lerman JL, Tooze JA, et al. Update of the Healthy Eating Index: HEl-2015. J Acad Nutr Diet 2018:118(9):1591-602.

34. Monge A, Lajous M, Ortiz-Panozo E, Rodriguez BL, Gongora JJ, LopezRidaura R. Western and Modern Mexican dietary patterns are directly associated with incident hypertension in Mexican women: a prospective follow-up study. Nutr J. 2018;17(1):21.

35. Park JE, Jung H, Lee JE. Dietary pattern and hypertension in Korean adults. Public Health Nutr. 2014;17(3):597-606.

36. Saneei P, Salehi-Abargouei A, Esmaillzadeh A, Azadbakht L. Influence of Dietary Approaches to Stop Hypertension (DASH) diet on blood pressure: a systematic review and meta-analysis on randomized controlled trials. Nutr Metab Cardiovascular Dis. 2014;24(12):1253-61.

37. Azadbakht L, Fard NR, Karimi M, Baghaei MH, Surkan PJ, Rahimi M, et al. Effects of the Dietary Approaches to Stop Hypertension (DASH) eating plan on cardiovascular risks among type 2 diabetic patients: a randomized crossover clinical trial. Diabetes Care. 2011;34(1):55-7.

38. Azadbakht L, Mirmiran P, Esmaillzadeh A, Azizi T, Azizi F. Beneficial effects of a Dietary Approaches to Stop Hypertension eating plan on features of the metabolic syndrome. Diabetes Care. 2005;28(12):2823-31.

39. Tiong XT, Nursara Shahirah A, Pun VC, Wong KY, Fong AYY, Sy RG, et al. The association of the dietary approach to stop hypertension (DASH) diet with blood pressure, glucose and lipid profiles in Malaysian and Philippines populations. Nutr Metab Cardiovascular Dis. 2018;28(8):856-63.

40. Yu E, Rimm E, Qi L, Rexrode K, Albert CM, Sun Q, et al. Diet, Lifestyle, Biomarkers, Genetic Factors, and Risk of Cardiovascular Disease in the Nurses' Health Studies. Am J Public Health. 2016;106(9):1616-23.

\section{Publisher's Note}

Springer Nature remains neutral with regard to jurisdictional claims in published maps and institutional affiliations.
Ready to submit your research? Choose BMC and benefit from:

- fast, convenient online submission

- thorough peer review by experienced researchers in your field

- rapid publication on acceptance

- support for research data, including large and complex data types

- gold Open Access which fosters wider collaboration and increased citations

- maximum visibility for your research: over $100 \mathrm{M}$ website views per year

At BMC, research is always in progress.

Learn more biomedcentral.com/submissions 